Please quote as: Leimeister, J. M.; Daum, M. \& Krcmar, H. (2004): Towards mobile communities for cancer patients: the case of krebsgemeinschaft.de. In: International Journal of Web Based Communities (IJWBC), Ausgabe/Number: 1, Vol. 1, Erscheinungsjahr/Year: 2004. Seiten/Pages: 58-70. 


\title{
Towards mobile communities for cancer patients: the case of krebsgemeinschaft.de
}

\author{
Jan Marco Leimeister, Miriam Daum and \\ Helmut Krcmar \\ Chair for Information Systems, \\ Technische Universität München, Germany \\ E-mail: leimeister@in.tum.de_E-mail: miriam.daum@in.tum.de \\ E-mail:krcmar@in.tum.de
}

\begin{abstract}
This article describes mobile virtual healthcare communities as a solution for meeting cancer patients' needs for information and interaction. After a short introduction into the German healthcare system and its potential starting points for virtual communities, the authors focus on cancer patients. They analyse their situation through field studies and identify information and interaction needs. On this basis, requirements for user centric socio-technical system design for cancer patients are derived. Since no existing offers meet these prerequisites, the authors work on piloting a mobile virtual community for cancer patients in Germany. Some of the identified user needs hint at an extension of web-based services for overcoming internet-related boundaries. New technological possibilities like mobile services and mobile devices are influencing virtual communities. Subjects like ubiquitous community access, new possibilities of user identification and location related services are of special interest since they might allow real 'anytime-anyplace' access to the community platform. But regardless of the vast (theoretical) technical possibilities of new mobile technologies for extending web-based services, only socially accepted, technically stable and economically feasible solutions can ensure sustainable success of mobile virtual healthcare communities.
\end{abstract}

Keywords: virtual communities; healthcare; mobile services; m-communities; patient information systems; online communities for patients.

Reference to this paper should be made as follows: Leimeister, J.M., Daum, M. and Krcmar, H. (2004) 'Towards mobile communities for cancer patients: the case of krebsgemeinschaft.de', Int. J. Web Based Communities, Vol. 1, No. 1, pp.58-70.

Biographical notes: Dipl. oec. Jan Marco Leimeister is a Researcher at the Information Systems Department, Hohenheim University, Germany. He manages the research project Community Online Services and Mobile Solutions (COSMOS), funded by the German Ministry for Research and Education. Prior to this, he graduated in Business Administration (majors in Information Systems, International Management, and Marketing) at the Hohenheim University and worked on different projects for companies like Daimler Chrysler, IBM, and Siemens Business Services. Since March 2003, he has been a Visiting Researcher at the Chair for Information Systems at Technische Universität München and since February 2004, a Visiting Researcher at the University of Maryland (UMBC).

Dipl. oec. Miriam Daum has been a Research Assistant at the Chair for Information Systems at Technische Universität München, Germany since 2003. Before moving to Munich, she studied Business Administration at Hohenheim 


\begin{abstract}
University, specialising in Controlling and Social Management (1995-2001). From 2001 to 2003, she was a research assistant at the Information Systems Department of Professor Dr. H. Krcmar at Hohenheim University. Her research interests are virtual communities, especially in the healthcare sector. She works on the research project COSMOS that focuses on the implementation and evaluation of virtual communities for cancer patients.

Professor Dr. Helmut Krcmar holds the Chair for Information Systems at Technische Universität München, Germany. He worked as a Post Doctoral Fellow at the IBM Los Angeles Scientific Center, as an Assistant Professor of Information Systems at the Leonard Stern School of Business, NYU, and at Baruch College, CUNY. From 1987 to 2002, he was Chair for Information Systems, Hohenheim University, Stuttgart. From 2000-2002 he served as Dean, Faculty of Business, Economics and Social Sciences. His research interests include Information and Knowledge Management, and CSCW. He was AIS-Council Europe 1996-1997, Chairman ECIS-1996, Co-Chair Doctoral Consortium ICIS-99, and Programme Co-Chair ICIS-2000.
\end{abstract}

\title{
1 Introduction
}

\subsection{Structure of the paper}

After the abstract, chapter 2 starts with an introduction into virtual communities. Consequently the German healthcare system is described in brief, followed by a scenario for a virtual healthcare community. Chapter 3 outlines the purpose and methodology of the project. The following chapter, 4 , describes preliminary empirical findings, beginning with the need analysis of cancer patients. After that, results of analyses on web-based information and interaction offers for cancer patients are summarised briefly. Implications of our empirical findings for the community engineering are described in chapter 5 and the first steps of system design are mentioned. The next section describes the implementation of our community platform for cancer patients. Chapter 6 emphasises possibilities of adding value to virtual communities for cancer patients through mobile services. It presents/introduces some mobile services, in particular for the healthcare sector. The paper ends with a summary and outlook for further research.

\subsection{Mobile virtual communities}

A virtual community (VC) can be defined as a group of people who gather because of a common interest, problem or task and whose members are independent of time and space for interacting [1-2]. For similar definitions see also [3-6]. VCs provide ubiquitous information and interaction spaces. For being accessible and usable at any time and from any place, information and communication technology (ICT) is a crucial element. Combining traditional internet technologies with the new capabilities of mobile networks is an approach for coping with this challenge. The vision of mobile virtual communities implies a bridge between technology and user requirements and assumes that synchronisation between different devices permits a seamless interaction. Mobile virtual communities have great potentials to serve ubiquitous needs. Such an omnipresent 
problem situation exists for instance in healthcare, when patients develop a desire for information and communication exceeding the offers of the treating physician. These information demands vary over time and during certain status of treatment and illness [7].

In order to achieve ubiquitous information and interaction spaces, we derive in the following design requirements for VCs that are transferred into the healthcare domain, particularly into the situation of cancer patients. Special emphasis is put on the possibilities and challenges of mobile technology.

\subsection{The German healthcare system}

The clients of the healthcare system are patients. Further actors can be classified in institutions from an organisational standpoint and in involved persons from a social standpoint. Institutions can either be supplier of goods and/or services like hospitals or cost units like insurances. Persons involved can either be part of an institution or more generally, part of the healthcare system or benefit recipient like patients. According to this structure, there can be several starting points for virtual communities (see Figure 1) corresponding to groups with a similar interest, problem or a common task. Examples are groups of physicians that want to share experiences beyond institutional boundaries or groups of members/employees of an insurance scheme that have the common interest of exchanging knowledge. And of course, patients with the same disease (like cancer), which will be the target group o this work.

Figure 1 Potential starting points for virtual communities in the healthcare system

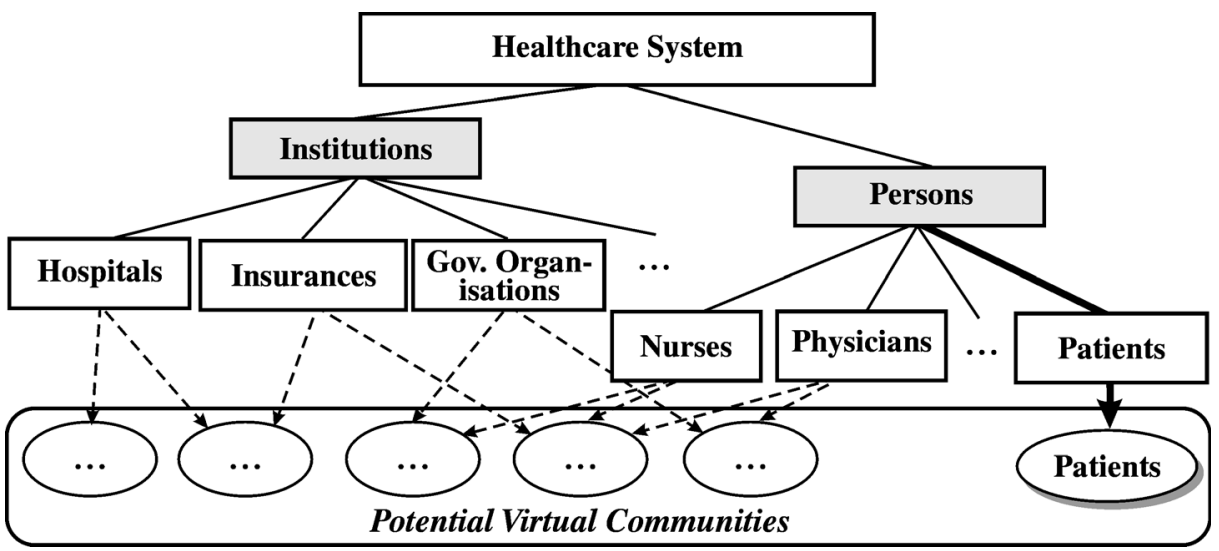

\subsection{Scenario: a day in Christina M. 's life in a virtual healthcare community}

One year ago, Christina, 34 years old, was feeling tired. She went to her physician and two days later, on a Friday afternoon, her physician told her: 'I regret to inform you that you have been diagnosed for leukaemia'. Christina went home, was shocked and afraid of the things to come. A good friend told her about a virtual community for leukaemia patients. There, she found a lot of information about diagnosis, treatment and answers to other questions. But, the most important thing was that she could share her feelings with other patients in the same or similar situation, and of the same age and having the same type of cancer. Beyond this, she could contact survivors of leukaemia. Christina realised 
that her life was not over. The stories of other patients encouraged her and gave her hope and strength. In this cancer community, people could understand her and her problems far better than her family and friends.

Today, Christina is one of the most active community members. Her personal assistant/mobile phone enables her to have access to her own data/story of illness, to medical databases, to a personal calendar with an e-mail reminder service for the next appointment, the internet and her cancer community. Christina can access her community from any place at any time. Christina likes to write e-mails whenever and wherever she wants to, especially when she has to go to the hospital for a longer stay. In her personal diary on the community platform, she writes down about how she feels. Her physician can access these data and interfere if something important occurs or can give her advice. In addition, the community offers her location-based services, enabling her to look for friends nearby or search for the next physician or pharmacy. And, if she is in a life-threatening situation, the mobile device enables her to send an emergency call via the mobile device to her physician or to the ambulance service so that she can be located easily.

\section{Purpose and methodology}

\subsection{Purpose}

The objective of the research project is to offer cancer patients a community platform that meets their needs. These specific needs are identified through ethnographic field studies, document analysis and interviews. The preliminary results show a platform where patients can exchange their opinions towards a certain drug, physician, therapy or their personal experiences might satisfy their needs. Since many patients do not have the time or the possibility, or they do not want to go to real self help group meetings, the virtual and mobile community is a possible way out of this problem. They can access their community providing information and contacts to other patients at any time and at any place. Furthermore, mobile devices offer new and interesting services in the healthcare sector.

\subsection{Research design}

Research design describes the key objectives of the research project, what methods will be used for data collection and analysis as well as how the research process shall take place. The objective of this venture is to plan, build, introduce and evaluate an IS-platform for cancer patients. Pilot projects are a special version of interventionistic science. They develop and implement technological innovations in their natural organisational and social environment [8].

The starting-point is a socio-organisational problem (in this case, the situation of cancer patients after returning from hospital). At the beginning, an analysis of cancer patients' situations will be performed in-depth through literature reviews and case studies, using interviews, questionnaires, observations and document analyses [9]. The results of the analysis are used for designing an IS-platform. This platform is implemented in the field and finally improvements in the system are made during the remainder of the project. At all times, on all levels, a continuous evaluation has to take 
place and thus iterative learning steps of the system developer can be augmented at all stages.

The objective of the field studies was to study cancer patients' needs and to analyse already available web-based offers for cancer patients. Therefore we analysed the situation of cancer patients in general with a standardised questionnaire, followed by indepth studies in five different cancer self-help groups with approximately 100 active members. We opted for this ethnographic analysis semi-structured interviews, observations and document analyses, following the tradition of using ethnographic analyses for system design in medical informatics [10-12]. The field studies and the experiences influenced the system design and requirements. As we know our particular population of users (these are cancer patients, relatives and friends) we were able to find out their specific information and interaction needs.

After that, web-based information and interaction offers were investigated. Finally, identified cancer patients' needs and already available offers were compared. The results of the analyses were used for designing the web-based virtual community platform, www.krebsgemeinschaft.de, using an iterative process model for system development (for further details on the system development process, please see also [13]). The platform was implemented in the field on August 18, 2002 and finally improvements in the system were made during the remainder of the project. At all times, on all levels, a continuous evaluation takes place and thus iterative learning steps of the system developer can be augmented at all stages.

Figure 2 Research plan

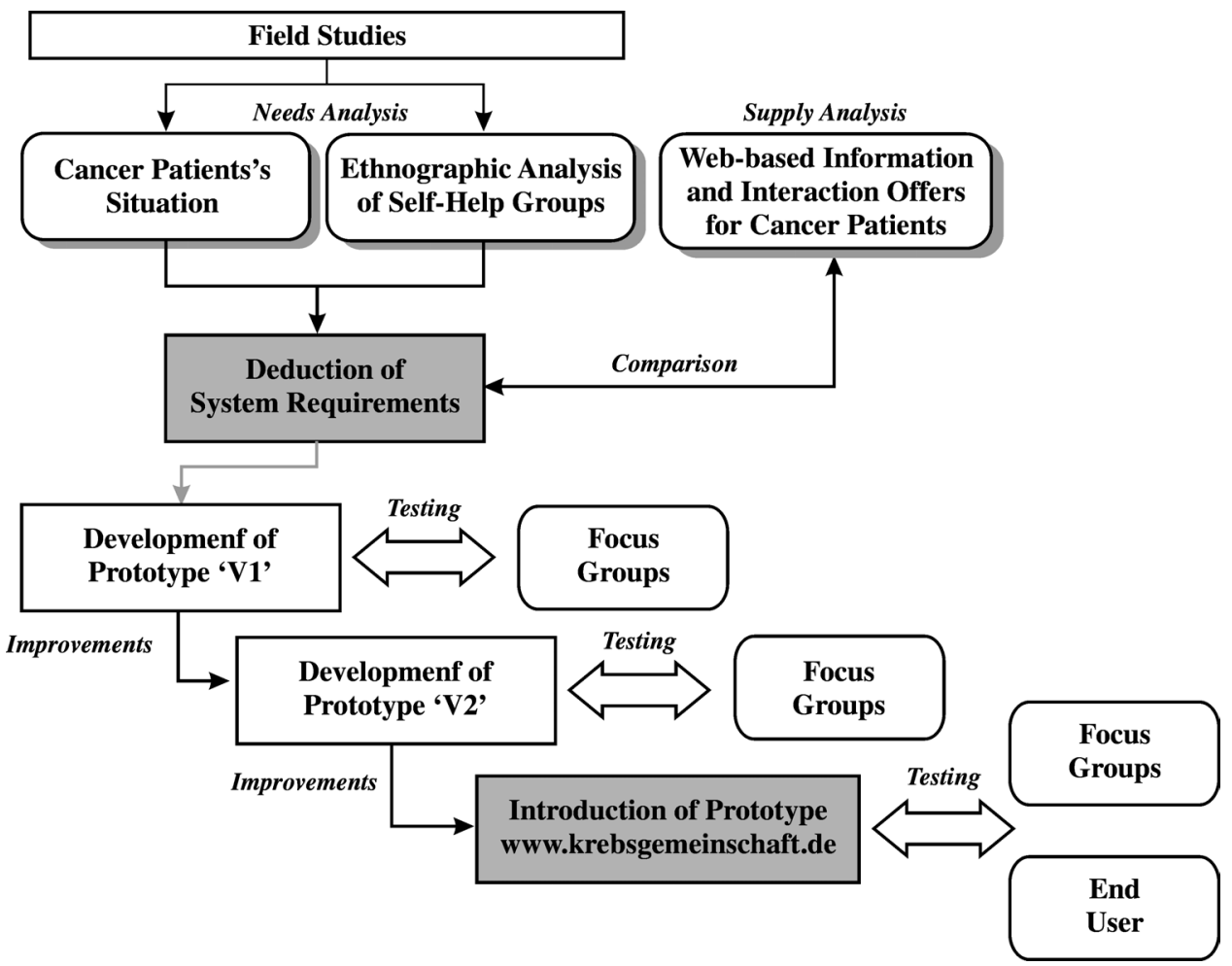




\section{Empirical findings}

\subsection{Needs analysis of cancer patients}

Patients very often develop high information demands, e. g., after a diagnosis of a disease or during medical treatment. Jones et al. [14] stated that $80 \%$ of the patients want as much information as possible. They might want to control diagnosis or take part in the decision process forfurther treatment based on diagnosis made.

During the European Week against Cancer (October 2002), a standardised questionnaire was distributed in Stuttgart, Germany to approximately 500 visitors. The rate of return was $23.2 \%$ (116 questionnaires). It was found that more than $60 \%$ of the cancer patients agreed with the question that their physician had a big information advantage. One third of them agreed partly that they wanted to look for information on the internet. A total of $29 \%$ of the female cancer patients used mobile phone as well as the internet. Formen, mobile phones were used by $56 \%$ and the internet by $44 \%$. More than two thirds agreed partly that they wanted to communicate more with other patients. These statements emphasised the need for web-based and/or mobile information and interaction services and showed the chances of success with such a platform.

Additionally, we conducted ethnographic analyses of self help groups. We conducted narrative interviews with self-help group leaders and several semi-structured interviews with group members. The results showed that lack of information and interaction possibilities for cancer patients and their relatives could be stated. The patients want and need information about their specific type of cancer, treatment or hospital. Most of the members of self-help groups found it important to share information and to speak with other patients in the same or similar situation. They gained new hope and got encouraged when they saw one of the members recovering. Even if the meetings just took place quarterly, the members called each other by telephone very often to get advice. Some members had a very long distance to cover (sometimes up to several hours drive) in order to get to their self-help group meetings. This fact underlines the importance of a self-help group for its members.

The use of materials and tools like mobile phones, personal digital assistants or the internet correlates with the average age of the group and the age of the members. In three out of five groups, the majority of members had mobile phones and up to a third already used the internet.

Unrestricted access to valid, understandable and relevant information, as well as the possibility to contact other patients of the self-help group at any time was considered very important. But this seems to be possible only for members of self-help groups and therefore not for the majority of cancer patients. Only 3\% of the cancer patients attend self-help group meetings [15]. Hence, our results confirm the demands of cancer patients, their relatives and friends for information and interaction services and the need for an offer also addressing patients not already associated with self-help-groups.

\subsection{Analysis of web-based information and interaction offers for cancer patients}

In order to analyse offers for cancer patients, two internet surveys have been conducted $[16,17]$. Until now (status May 2002), there are only a few websites with significant 
levels of interaction that could be called a community at an European level (German or English speaking). These are less than $6 \%$ of cancer related websites. Most of the studied websites (a total of 276) offered information, either medical or personal, like those based on personal experiences. On the German and English internet, we could not identify any offer concerning mobile services' support for access through mobile devices.

For further information and the results of the years 2001 and 2002 see [16,17].

\section{Implications for community engineering}

\subsection{First steps of system design}

Our research and preliminary results have shown so far, that a socio-technical design for virtual healthcare communities has to consider (among others) the following issues for being successful (see also [2]):

- Creation of a virtual information and interaction space with appropriate communication channels according to cancer patients needs.

- Trustworthy operators (no financial interest in the subject, explicit competence in medical issues, etc.) of the community platform and transparency about the source of funds in order to support the development of trust.

- Competent content managers for the quality assurance of centrally provided content.

- Access to right structures that support the development of trust and that also support real-life situations and interactions. Similar results can be found at e.g. [6].

- The provision of tools for working with shared material for supporting group activities that have been successfully used in computer-supported meetings for a longer time [18].

- The facility for an active community management to remotely monitor and control the participants' information and interaction spaces and the tools within the system (an equivalent for the role of a self-help group leader in order to avoid problems known from real-life groups like charlatanism, etc.).

- A clear and strict separation of provider generated and user generated content (due to German legal restrictions, especially for avoiding liability and copyright problems).

Cancer patients are migrating between different contexts, such as different hospitals and medical centres, work and home. Hospitals or medical professionals remain their most important source of information [19], but information and interaction desires are ubiquitous and don't stick to office hours of physicians. There are also other needs than just medical knowledge retrieval. The desire for social peer-to-peer interaction and emotional support is independent of time, cost or stage of disease and mobility and also of structures required by self-help groups [15]. Opening oneself to others, dealing with very intimate and private issues requires an intimate environment. Trust could be, as always, identified as a very critical issue.

We suggest (in accordance with [20]) providing useful digital tools and digital materials for cancer patients. Tools allow modification and processing of material. In tradition of Computer Supported Collaborative Work (CSCW), tools can enable users to 
communicate, to coordinate common tasks or to cooperate at shared material [21]. Trust-related issues can be approached through a high priority of data security and a highly specialised and scalable authorisation concept.

Therefore, we propose an approach using the room metaphor for software design (for details see also [22]). Its advantages, from the point of view of software engineering, lie in several aspects: It allows an intuitive handling of documents, easy to adopt access to right structures and it supports existing ways of cooperation and coordination in social structures [22]. The following types of information and interaction spaces seem to be useful for cancer patients: A private room, where the user can store private information, documents and links, and have direct communication with others only after having invited them to join, called 'my site'. In a public room, all members and visitors of the virtual community can see all information and documents and search for information. This is represented through those parts of the website where no log-in or registration is required. Also needed is a group room that is restricted to members of a group (e.g. like the self-help groups) and provides access to all documents in this group room and all group related issues to all group members. This is especially backed by the results of our ethnographic studies of self-help groups, where almost all active members stated strong interest in maintaining their used social group structures combined with the wish for unrestricted access to information and spontaneous interaction with others. That means that the user can choose if he/she wants to be anonymous, a lurker, a registered member, or be active or passive. He/she can decide how much other users get to know about $\mathrm{him} /$ her. It is possible to change the personal profile whenever needed.

\subsection{Architecture and system requirements for a community-platform for cancer patients}

In order to fulfil diverse requirements on a community platform, a client server solution is utilised whose architecture consists mostly of three layers (data, application and presentation layer). This architecture allows a high scaling and flexibility of the system as well as extensions by contextsensitive elements. It also offers the advantage of making a modular structure of the platform possible. Furthermore, different standards as for example, XML/XSL, HTML, WML, JDBC and HTTP(S), are supported by this system, thus permitting a support of any access device using a browser (web-browser, WAP-mobile-browser, etc.).

It is possible to communicate between clients and servers as they are spread over several computers. Since they carry the major part of the load, systems can be scaled strongly. This layer receives inquiries of users in HTML or WML, converts them in XML and responds in XML-pages, which are again converted into HTML- or WML-pages. The protocol used for communication between the client and the presentation layer, is mostly http, but other protocols, in particular WAP for mobile devices, may also be used.

The application layer responds to inquiries of the presentation layer and takes charge of central functions of the administration. Nearly all the functions of the community are provided on the server side. Typical functions are for instance calendaring or chat modules.

In the data retention layer, information is saved permanently. The system disposes interfaces that are wrapped over the data retention systems and which can be applied to the data storage. According to dominant standards, SQL-compatible databases are 
supported. In the ideal case, it is irrelevant for the application layer which system is used for data storage. It accesses structures that are reflected on the respectively available data retention systems. Thereby, the application components can be developed independently of the system on which they are based in each case. Thus, for example, the integration of existing data sources can be managed.

Figure 3 Three-layer-architecture of community-support-systems

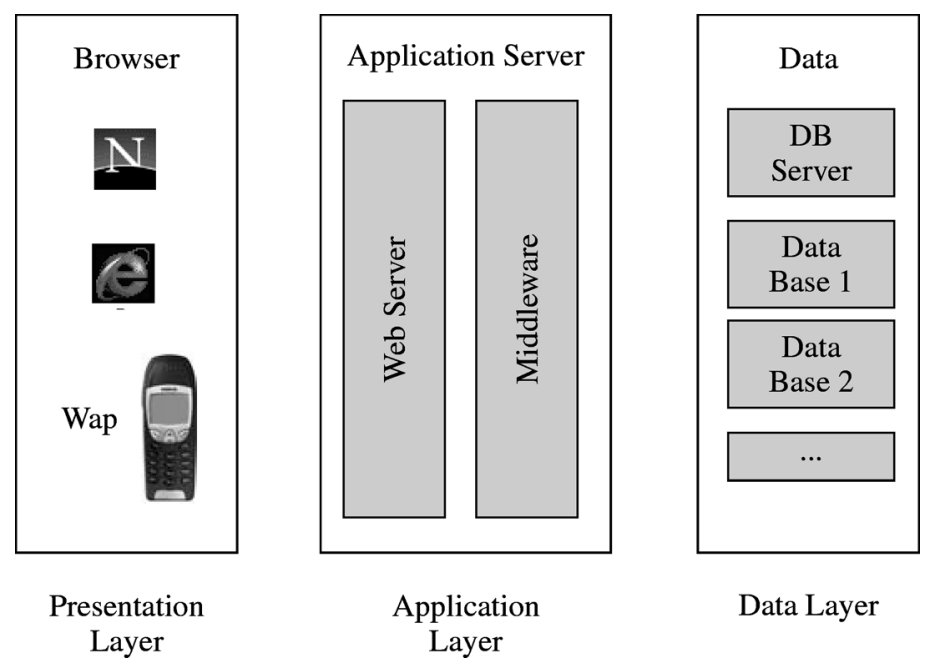

\section{Adding value to virtual communities through mobile services}

The architecture of the community platform and the application of XML as a data retention format enables the general extension of the community platform through mobile services. Mobile services can add value to traditional web-based communities for several reasons. They extend and/or improve already existing services or they allow new services that have not been possible before. Figure 4 visualises some possibly value-adding services.

Through ubiquitous access to already existing web-based offers, community members have, for example, access to information and the possibility for interaction with others at any time and at any place. This means that they are no longer bound to their personal computers at home or at work.

The second point concerns secure and easy user authentication. Users of mobile devices normally carry their devices with them and their devices are technically easy to identify (e.g. via the SIM-Card and/or the device ID). This and a personal PIN allows easy and feasible possibilities for user identification (e.g. automated log-in procedures, etc.).

Another improvement concerns existing reminder services on the internet [23]. SMSbased reminder services supplement these services, for instance, reminders for the next medical examination or especially for drugs/pills, which is efficient [24]. Most devices are 'always on' and nearby to users. Therefore, the reminders reach their addressees more often in contrast to mailboxes on the internet. 
Figure 4 Mobile services for adding value to virtual communities

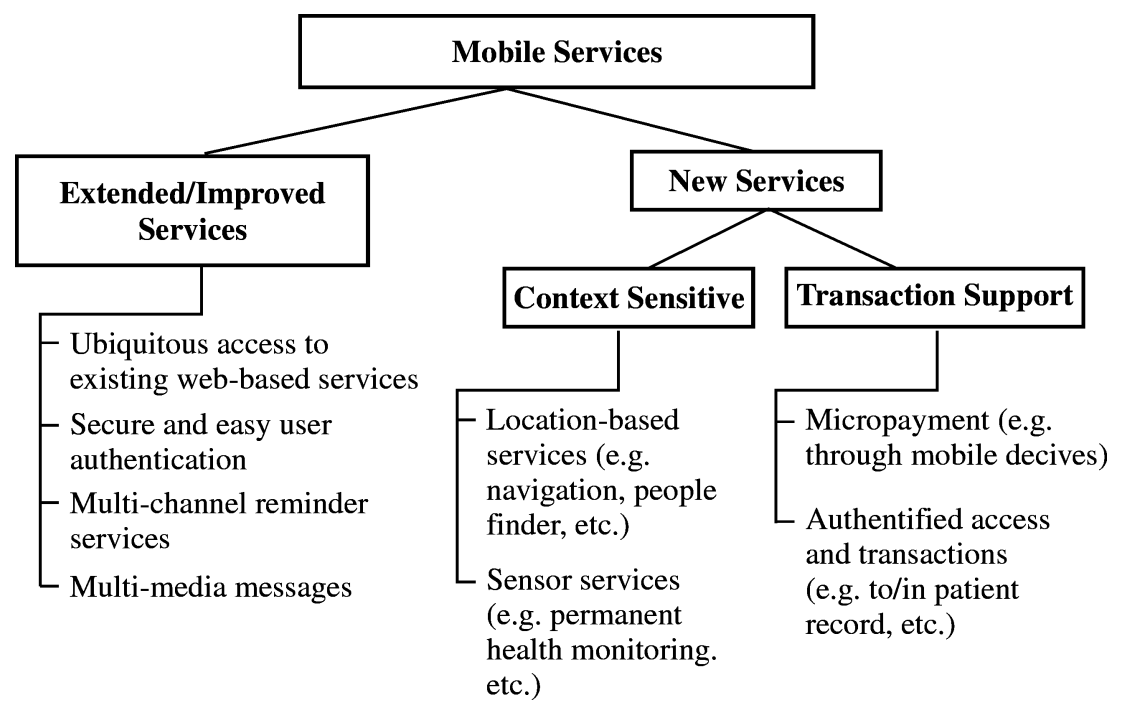

The last service in this category is multi-media messaging. It describes the integration of voice mail, e-mail and fax applications into one messaging display.

The other class of mobile services are the 'new services' that are only made possible through the new possibilities of mobile devices. These devices are capable of supporting context sensitive and location-based services. That means, for instance, that awareness services for who (buddy) or what (location) is around can be perceived and processed by the mobile devices. These services can either be push or pull services. A push service means that information is offered by the mobile device without any previous request by the user, e.g. that a certain person/location is nearby. If it is a pull service, the user has to start a request to get the information he/she demands. Furthermore, it is possible to choose context and location attributes for selecting contacts. People can get awareness information about their buddies and also get a message generated by the system that a certain person (so far unknown) is around and that this person is interested in the same location, e.g. a music band. This kind of matchmaking is generated automatically by the system and enables spontaneous meetings. It discovers/identifies similarities and displays them [25]. Of course the users can specify rules and parameters like when, how and for whom they want to be reachable. One imaginable scenario is that all people who belong to a certain group (like breast cancer patients in general) and are near a self-help group meeting currently taking place, get a welcome message and an invitation to join the group.

Another new kind of services in the medical field are emergency services [26]. It is possible to monitor parameters like blood pressure, pulse rate, temperature or electrocardiograms. They can be transmitted to a service centre or to a physician. If necessary in life-threatening situations, an emergency call can be generated automatically and through the location/positioning service the patient can be found easily [27]. Another project [28] deals with location-based information systems. It is possible via a mobile device to find the way to almost every location. The device shows the user a model of the surroundings as well as information about the location or the objects and buildings 
nearby. Any geographical position is connected with the information required is made possible through a Global Position System (GPS) and mobile internet access. Thus, a digital model of the current surroundings shows on the display monitor of the device. Furthermore, it is possible to post virtual notes/messages bound to a location and to comment on them.

Further, a new possible category of new mobile services deals e.g. with transaction support. For instance, micro-payment refers to the possibility of paying via a mobile phone. The mobile device is connected with a bank account or the phone bill is charged. In order to pay a taxi driver through the internet, all you have to do is to enter your personal PIN and than the money is transferred [29]. But, there are many more possible applications to come in the field of mobile services. The challenge for community engineering lies in identifying target group relevant services and integrating these services into a community platform. In order to be prepared for new mobile services, we have chosen an architecture for the community platform for cancer patients that provides us with a maximum of flexibility referring to development and integration of new services towards the vision of mobile virtual communities for cancer patients.

\section{Concluding remarks and outlook for further research}

Mobile virtual communities are very promising approaches for overcoming information asymmetries and for supporting interaction in the healthcare sector in general. Especially for cancer patients, it seems to be a very promising model, since cancer patients have strong and ubiquitous demands for valid and trustworthy information and intensive wishes for empathy and interaction with other peers in similar situations. We have shown on the basis of in-depth field studies, how requirements for community engineering and system development in this domain need to look like. The development of the web-based community-platform, www.krebsgemeinschaft.de, has confirmed to a considerable extent that these are the first identified requirements. Mobile services have the potential to add significant value to virtual communities. Especially, the aspects of ubiquitous access to a community and its members and services as well as new services enabled through new mobile technologies seem very promising. However, further research is essential e.g. on the acceptance of mobile devices, usability issues and reasonable pricing models for usage of mobile services.

\section{Acknowledgement}

This paper is based on the research project COSMOS . It is a joint research project of Hohenheim University, and Technische Universitaet, Muenchen, $\mathrm{O}_{2}$ Germany. The project is funded by the German Ministry of Research and Education under contract No FKZ 01 HW 0107 - 01 HW 0110. For further information, please visit the website: http://www.cosmos-community.org. 


\section{References}

1 Klein, A., Leimeister, J.M. and Krcmar, H. (2001) 'Virtuelle healthcare communities:, in Baumgarten, U., Krcmar, H., Reichwald, R. and Schlichter, J. (Eds.): Community Online Services and Mobile Solutions, München, Technische Universität München, pp.17-30.

2 Leimeister, J.M., Daum, M. and Krcmar, H. (2002) 'Mobile virtual healthcare communities: an approach to community engineering for cancer patients', Proceedings of European Conference on Information Systems (ECIS), Gdansk.

3 Armstrong, A. and Hagel III, J. (1996) 'The real value of online communities', Harvard Business Review, Vol. 74, No. 3, pp.134-141.

4 Preece, J. (2000) 'Online communities - designing usability', Supporting Sociability, Chichester, New York, Weinheim, Brisbane, Singapore, Tokio, John Wiley and Sons.

5 Schubert, P. (1999) 'Virtuelle transaktionsgemeinschaften im electronic commerce: management, marketing und soziale umwelt', in Schmid, N., Szypersky, B.; Scheer, A-W., Pernul, G., Klein, S. (Eds.): Electronic Commerce, Vol. Band 1, Lohmar, Köln, Josef Eul Verlag.

6 Mynatt, E.D., Adler, A., Ito, M. and O’Day, V. (1997) 'Design for network communities', Proceedings of Proceedings of the Computer Human Interaction Conference (CHI 97), pp.210-217.

7 Leydon, G.M., Boulton, M., Moynihan, C., Jones, A., Mossman, J., Boudioni, M. and McPherson, K. (2000) 'Cancer patients' information needs and information seeking behaviour: in depth interview study', British Medical Journal, Vol. 320, No. 7239, pp.909-913.

8 Schwabe, G. and Krcmar, H. (2000) 'Piloting a socio-technical innovation', Proceedings of the 8th European Conference on Information Systems ECIS 2000, Vienna, Publishe, pp.S.132-139.

9 Yin, R.K. (1989) 'Research design issues in using the case study method to study management information systems', in Cash, J.I. and Lawrence, P.R. (Eds.): The Information Systems Research Challenge: Qualitative Research Methods, Boston, Mass.: Harvard Press, pp.1-6.

10 Fafchamps, D., Young, C. and Tang, P. (1991) 'Modelling work practices', Proceedings of 15th Symposium on Computer Applications in Medical Care (SCAMC), New York, pp.788-792.

11 Forsythe, D.E. (1992) 'Using ethnography to build a working system: rethinking basic design assumptions', Proceedings of 16th Symposium on Computer Applications in Medical Care (SCAMC), New York, pp.510-514.

12 Forsythe, D.E. and Buchanan, B.G. (1991) 'Broadening our approach to evaluating medical information systems', Proceedings of 15th Symposium on Computer Applications in Medical Care, New York, pp.8-12.

13 Arnold, Y., Leimeister, J.M. and Krcmar, H. (2003) 'COPEP: a development process model for a community platform for cancer patients', Proceedings of XIth European Conference on Information Systems (ECIS), Naples.

14 Jones, R., Pearson, J., McGregor, S., Gilmour, W.H., Atkinson, J.M., Barrett, A., Cawsey, A.J. and McEwen, J. (1999) 'Cross sectional survey of patients' satisfaction with information about cancer', British Medical Journal, Vol. 319, No. 7219, pp.1247-1248.

15 Hasebrook, J. (1993) Krebs-Selbsthilfegruppen - Untersuchungen zu Bedarf, Funktionen und Wirksamkeit, in Haag, F.A. and Muthny, G. (Eds.): Onkologie im psychosozialen Kontext - Spektrum psychoonkologischer Forschung, zentrale Ergebnisse und klinische Bedeutung, Heidelberg: Roland Asanger Verlag.

16 Daum, M., Klein, A., Leimeister, J.M. and Krcmar, H. (2001) Webbasierte Informationsund Interaktionsangebote für Onkologiepatienten - Ein Überblick, Working Paper No. 109, Hohenheim University, Chair for Information Systems. 
17 Daum, M., Klein, A., Leimeister, J.M. and Krcmar, H. (2002) Webbasierte Informationsund Interaktionsangebote für Onkologiepatienten 2002 - Ein Überblick. Working Paper No. 111, Hohenheim University, Chair for Information Systems.

18 Nunamaker, J.F., Briggs, R.O., Mittleman, D.D., Vogel, D.R. and Balthazard, P.A. (1997) 'Lessons from a dozen years of group support systems research: a discussion of lab and field findings', Journal of Management Information Systems, Vol. 13, No. 3, p.163-207.

19 Kaminski, E., Thomas, R.J., Charnley, S. and Mackay, J. (2001) 'Measuring patients response to received information', European Journal of Cancer, Vol. 37, Supplement 6, pp.387.

20 Gryczan, G. and Züllighoven, H. (1992) 'Objektorientierte systementwicklung: leitbild und entwicklungsdokumente', Informatik Spektrum, Vol. 15, No. 5, pp.264-272.

21 Krcmar, H. and Klein, A. (2001) 'Computer supported cooperative work', in Mertens, P.U.A. (Ed.): Lexikon der Wirtschaftsinformatik, Berlin: Springer, pp.113-114.

22 Schwabe, G. and Krcmar, H. (2000) 'Digital material in a political work context - the case of cuparla', Proceedings of Proceedings of the 8th European Conference on Information Systems ECIS.

23 An example for an e-mail reminder service for the next physical examination for breast cancer patients, 27 February, http://www.nabco.org/index.php/30

24 For examples see M-Pill, a drug reminder per sms, 27 Febuary, http://www.m-pill.com/ as well as m-therapy http://www.m-therapy.de/ or cura call, a vaccination or a preventive medical check-up reminder per SMS http://www.dicomzip.de/.

25 Koch, M., Groh, G. and Hillebrand, C. (2002) 'Extending online communities into the real world', Proceedings of AMCIS 2002, Dallas.

26 Helpino is a service for persons in emergency situations in general, 27 February, http://www.helpino.com/

27 Example for Telemedical services: Vitaphone, 27 February, http://www.vitaphone.de News Services for patients with heart diseases or for diabetic patients: Diabetiker in Hannover, 27 February, http://www.diabetiker-hannover.de/diab_hannover/news_frame.htm Internet based registration of glucose data: Medical Software Systems, 27 February, http://www.mss-gmbh.de/diabhh.shtml.

28 Spatial World Models for Mobile Context-Aware Applications, 27 February, http://www.nexus.uni-stuttgart.de/

29 Example for Payment Services per cell phone, 27 February, http://www.paybox.de. 